\title{
MISCELLANEOUS
}

\section{Respiratory symptoms in patients with treated hypothyroidism and inflammatory bowel disease}

\author{
S S Birring, A J Morgan, B Prudon, T M McKeever, S A Lewis, J F Falconer Smith, \\ R J Robinson, J R Britton, I D Pavord
}

Thorax 2003;58:533-536

See end of article for authors' affiliations

.....................

Correspondence to: Dr S S Birring, Institute for Lung Health, Department of Respiratory Medicine, Glenfield Hospital, Leicester, LE3 9QP, UK. sb134@le.ac.uk

Accepted for publication 3 March 2003

\begin{abstract}
Background: Patients with idiopathic chronic cough and unexplained aifflow obstruction in non-smokers have been shown to have an increased prevalence of hypothyroidism and other organ specific autoimmune disorders. Whether patients with hypothyroidism have an increased prevalence of respiratory symptoms is unknown.

Methods: The prevalence of respiratory symptoms was assessed in 124 patients with treated hypothyroidism recruited from primary and secondary care, 64 outpatients with inflammatory bowel disease, and 1346 control adults recruited randomly from the electoral register in a case-control study. Respiratory symptoms and smoking history were assessed by a respiratory symptom questionnaire.

Results: After adjustment for age, sex and smoking, symptoms of breathlessness and sputum production were more prevalent in both patient populations than in controls (odds ratios for hypothyroidism and inflammatory bowel disease; breathlessness: $3.1(95 \% \mathrm{Cl} 2.1$ to 4.6$)$ and $3.4(95 \% \mathrm{Cl} 2.0$ to 6.0), respectively; sputum production: $2.7(95 \% \mathrm{Cl} 1.6$ to 4.5$)$ and $2.5(95 \% \mathrm{Cl} 1.2$ to 5.0$)$, respectively). Cough during the day and night was significantly more prevalent in patients with hypothyroidism (1.8 (95\% Cl 1.2 to 2.9$)$ ) and approached significance in those with inflammatory bowel disease (1.8 (95\% Cl 1.0 to 3.4)). Wheeze and nocturnal cough were no more prevalent in either disease population than in controls.

Conclusion: There is a significantly increased prevalence of respiratory symptoms in patients with hypothyroidism or inflammatory bowel disease compared with controls recruited from the general population. Further work is required to determine whether similar differences are seen in comparison with hospital based controls. These findings support the hypothesis that there is a link between autoimmune hypothyroidism and respiratory disease.
\end{abstract}

l: a recent case-control study we noted that hypothyroidism and other organ specific autoimmune disorders were eight times more likely to be present in patients with idiopathic chronic cough than in age and sex matched controls. ${ }^{1}$ We have also found an excess of organ specific autoimmune disease in non-smoking patients with unexplained fixed airflow obstruction. ${ }^{2}$ In both studies the strongest association was with autoimmune hypothyroidism and the subjects were treated with thyroxine, implying that the association is independent of thyroid hormone status. A link between thyroid disease and respiratory disease independent of thyroid hormone status is supported by a prospective community study which showed that the odds ratio of death from respiratory disease was 2.8 in subjects with a normal thyroxine level but suppressed thyrotropin levels. ${ }^{3}$

The mechanism for the possible association between autoimmune hypothyroidism and respiratory disease is unclear, but one possibility is homing of activated inflammatory cells from the primary site of autoimmune inflammation to the lung. An analogous mechanism is thought to be responsible for respiratory complications of inflammatory bowel disease. ${ }^{4}$ However, the link between inflammatory bowel disease and respiratory morbidity is based on case reports and case series and there are no data from controlled studies showing an association. ${ }^{5}$ In this case-control study we set out to investigate the prevalence of respiratory symptoms in patients with treated hypothyroidism and to compare the prevalence and nature of respiratory morbidity with that seen in a cohort of patients with inflammatory bowel disease and a control population.

\section{METHODS \\ Subjects}

One hundred and seventy five patients with treated hypothyroidism were randomly chosen from the Leicestershire Thyroid Register. This is a register of patients diagnosed with primary hypothyroidism from primary $(48 \%)$ and secondary care $(52 \%)$. All patients at the time of diagnosis had raised thyroid stimulating hormone levels with suppressed thyroxine levels not due to treatment or surgery. At the time of completion of the respiratory questionnaire all patients were on appropriate thyroid replacement therapy and were biochemically euthyroid. Patients with inflammatory bowel disease were recruited prospectively from consecutive patients attending a gastroenterology outpatient clinic between September to December 2001 who met the study criteria. All patients had ulcerative colitis or Crohn's disease confirmed histologically and were at various stages of control. Disease activity was assessed and scored by a consultant gastroenterologist using the Simple Index of Crohn's Disease Activity ${ }^{6}$ and a Simple Clinical Colitis Activity Index. ${ }^{7}$ Controls comprised 1346 individuals aged 27-80 years from a local authority area of Nottingham who had participated in a previously described study investigating the effect of diet on decline in lung function. ${ }^{89}$ They were originally identified by systematic sampling from a random starting point in the electoral register. Their area of residence was similar in socioeconomic and geographical characteristics to the area from which the hypothyroid and inflammatory bowel patients were recruited.

Patients were asked for their consent to participate and the protocol was approved by the Leicestershire ethics committee. 


\begin{tabular}{llll} 
Table 1 & \multicolumn{3}{l}{ Subject characteristics } \\
\hline \multicolumn{5}{c}{$\begin{array}{l}\text { Controls } \\
(\mathrm{n}=1346)\end{array}$} & $\begin{array}{l}\text { Hypothyroidism } \\
(\mathrm{n}=124)\end{array}$ & IBD $(\mathrm{n}=64)$ \\
\hline Male (\%) & $668(50)$ & $18(15)$ & $29(45)$ \\
Age (years) & $56(12)$ & $56(14)$ & $45(14)$ \\
Smoking & & & \\
Never (\%) & $679(50)$ & $62(50)$ & $30(47)$ \\
Current (\%) & $155(12)$ & $11(9)$ & $11(17)$ \\
Ex-smokers (\%) & $512(38)$ & $51(41)$ & $23(36)$ \\
Pack years & $19(21)$ & $18(18)$ & $17(13)$ \\
\hline \multicolumn{5}{l}{ Values for age and pack years of smoking are mean (SD). Mean for } \\
pack years does not include non-smokers. \\
IBD=inflammatory bowel disease.
\end{tabular}

\section{Questionnaire}

Patients with hypothyroidism completed a questionnaire on smoking, respiratory symptoms (breathlessness: "Do you ever have trouble breathing?"; cough: "Do you usually cough during the day, or at night, in the winter?"; sputum: "Do you usually bring up any phlegm from your chest during the day, or at night, in the winter?"; nocturnal cough: "Have you ever been woken by an attack of coughing at any time in the last 12 months?"; and wheeze: "Have you had wheezing or whistling in your chest in the last 12 months?"), and recent upper respiratory tract infections. The questionnaire was adapted from the IUATLD questionnaire ${ }^{10}$ and was sent by mail outside the flu and grass pollen allergy seasons. Control subjects and patients with inflammatory bowel disease completed the same questionnaire during a visit to hospital or local clinic.

\section{Analysis of data}

Multiple logistic regression was performed in STATA version 7 (Stata Corporation, Texas, USA) to estimate the chance of having respiratory symptoms in the presence of hypothyroidism and inflammatory bowel disease independent of age, sex, and smoking (status and pack years). The hypothyroidism and inflammatory bowel disease groups were restricted to those within the age range of the control population for analysis.
Table 2 Prevalence of respiratory symptoms

\begin{tabular}{llll}
\hline & $\begin{array}{l}\text { Controls } \\
(\mathrm{n}=1346)\end{array}$ & $\begin{array}{l}\text { Hypothyroidism } \\
(\mathrm{n}=124)\end{array}$ & IBD $(\mathrm{n}=64)$ \\
\hline Breathlessness & $215(16)$ & $49(40)$ & $23(36)$ \\
Sputum & $131(10)$ & $23(19)$ & $11(18)$ \\
Cough & $212(16)$ & $31(25)$ & $15(24)$ \\
Nocturnal cough & $334(25)$ & $39(32)$ & $15(23)$ \\
Wheeze & $343(26)$ & $35(29)$ & $17(27)$ \\
\hline \multicolumn{4}{l}{ Values are number $(\%)$. IBD=inflammatory bowel disease. }
\end{tabular}

\section{RESULTS}

One hundred and twenty four patients with hypothyroidism $(71 \%), 1346$ controls $(51 \%)$, and 64 patients with inflammatory bowel disease (22 with Crohn's disease) completed the questionnaire. One hundred and six patients with hypothyroidism $(86 \%)$ were female and $16(13 \%)$ of patients self-reported the presence of a goitre. In other respects the characteristics of the subjects in the three groups were similar (table 1). After adjustment for age, sex, and smoking, symptoms of breathlessness and sputum production were more prevalent in both patient populations than in controls (odds ratio (OR) for hypothyroidism and inflammatory bowel disease groups: breathlessness 3.1 (95\% CI 2.1 to 4.6 ), $\mathrm{p}<0.001$ and 3.4 (95\% CI 2.0 to 6.0 ), $\mathrm{p}<0.001$; sputum 2.7 (95\% CI 1.6 to 4.5$), \mathrm{p}<0.001$ and $2.5(95 \%$ CI 1.2 to 5.0$), p=0.01$; fig 1 ). Cough was significantly more prevalent in patients with hypothyroidism (OR 1.8 (95\% CI 1.2 to 2.9), p<0.01) and approached significance in patients with inflammatory bowel disease (OR 1.8 (95\% CI 1.0 to 3.4), $\mathrm{p}=0.057$ ). Wheeze and nocturnal cough were no more prevalent in either disease population than in controls (table 2, fig 1). These odds ratios remained significant when hypothyroid patients with a goitre and patients with ulcerative colitis were excluded. Patients with Crohn's disease were 1.4-3.0 times more likely to report respiratory symptoms than patients with ulcerative colitis, and there was a trend for those with active inflammatory bowel disease to report more symptoms than those whose inflammatory bowel disease was inactive, although the difference did not reach statistical significance. There were

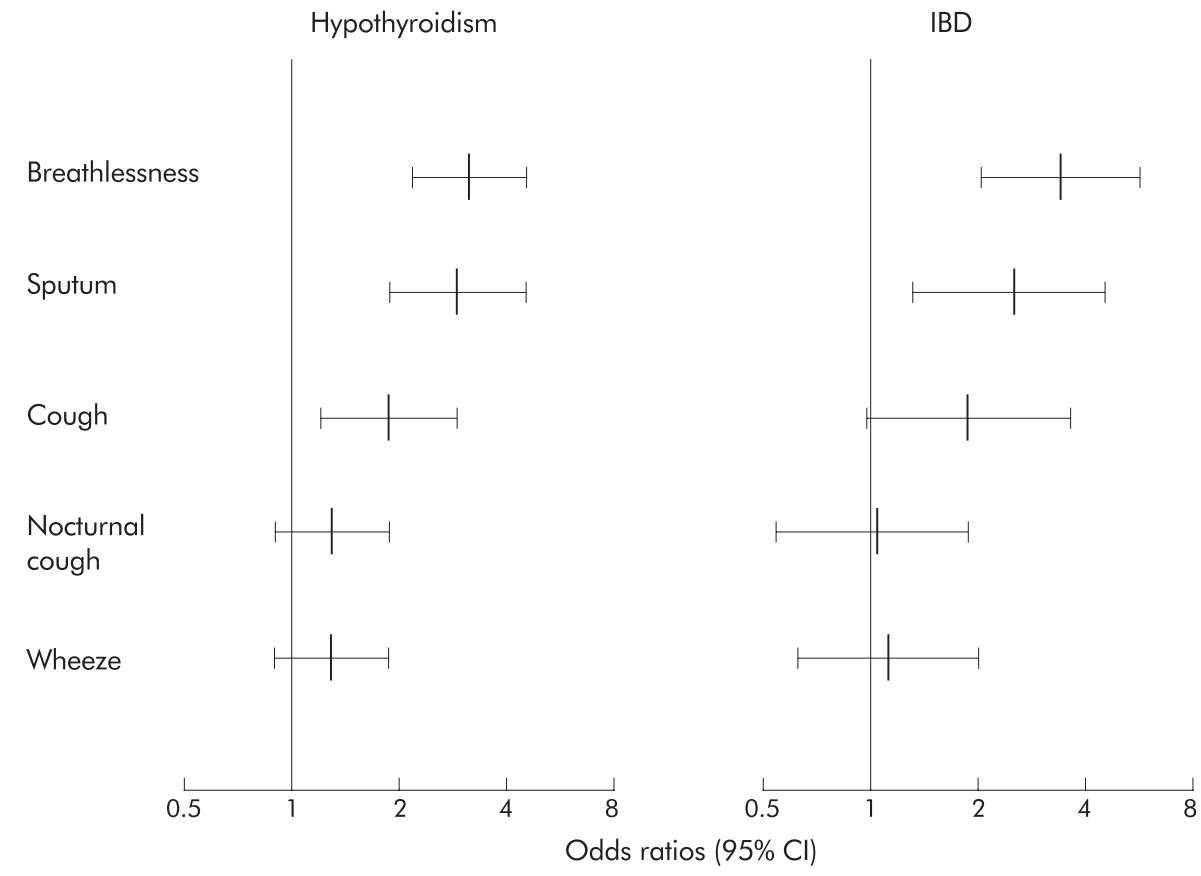

Figure 1 Odds ratio (95\% confidence intervals) of reporting respiratory symptoms in patients with treated hypothyroidism or inflammatory bowel disease (IBD) compared with controls after correction for age, sex, and pack years of smoking. 
no significant differences between groups in the presence of a head cold, sore throat, flu, or chest infection in the previous week.

\section{DISCUSSION}

We have shown a significantly increased prevalence of respiratory symptoms in subjects with hypothyroidism or inflammatory bowel disease. The increase seen in subjects with hypothyroidism was similar to that seen in those with inflammatory bowel disease for breathlessness, cough, and sputum production. This is the first demonstration of increased respiratory morbidity in subjects with treated hypothyroidism.

Our data support the widely held view that inflammatory bowel disease is associated with respiratory morbidity. There was a suggestion that patients with Crohn's disease and active inflammatory bowel disease had more respiratory symptoms than patients with ulcerative colitis and non-active disease, which is contrary to previous reports. ${ }^{11}$ However, the main purpose of the inflammatory bowel disease group was to serve as a disease control group and this study was not sufficiently powered to investigate differences within the inflammatory bowel disease group. Larger studies are required to investigate the differences in respiratory complications between patients with Crohn's disease and ulcerative colitis and their relationship with bowel disease activity.

There was a striking similarity in the profile of reported symptoms in patients with hypothyroidism and those with inflammatory bowel disease, suggesting a common underlying pathophysiology of these symptoms. The absence of wheeze and nocturnal symptoms argue against asthma; the symptom profile is more consistent with chronic obstructive pulmonary disease and chronic bronchitis. In support of this, the airway conditions associated with inflammatory bowel disease include chronic bronchitis, chronic obstructive pulmonary disease, and bronchiectasis, ${ }^{5}$ and hypothyroidism has been linked to cough and chronic obstructive pulmonary disease in non-smokers. ${ }^{12}$ We have considered the possibility that the respiratory symptoms in patients with treated hypothyroidism may be caused by the presence of a goitre, although this seems unlikely because the association between hypothyroidism and respiratory symptoms remained significant even after those with a goitre were excluded. The presence of airway symptoms such as sputum production and cough increases our confidence that we are detecting respiratory disease and not cardiac complications of hypothyroidism.

A causal association between organ specific autoimmune disease such as hypothyroidism and respiratory disorders is plausible. Autoimmunity is the most common cause of hypothyroidism, accounting for over $90 \%$ of non-iatrogenic cases. ${ }^{12}$ The lungs and many organs involved in autoimmune disorders share common embryological origins with foregut derivatives, and it is possible that homing of activated inflammatory cells into the pulmonary compartment as well as the primary site of autoimmune inflammation may cause airway wall inflammation and symptoms. An alternative and intriguing mechanism is that the respiratory symptoms might be the consequence of a hitherto unrecognised autoimmune bronchitis and that the association with other diseases simply reflects the well recognised association between different organ specific autoimmune diseases. The concept that some airway disorders are caused by immune dysregulation is supported by the presence of cough, airflow obstruction, and lymphocytic airway inflammation in Crohn's disease, ${ }^{45}$ coeliac disease, ${ }^{13}$ rheumatoid arthritis, ${ }^{14}$ Sjogren's disease, ${ }^{15}$ and posttransplant chronic lung rejection. ${ }^{16}$ Furthermore, we have recently shown that, as well as being associated with organ specific autoimmune disease, idiopathic chronic cough is associated with a bronchoalveolar lymphocytosis. ${ }^{17}$
One limitation of the study is a possible reporting bias, with control subjects reporting fewer symptoms than patients because they had attended twice during the previous 10 years and were perhaps more likely to be healthy. However, we feel this is unlikely to have had an important effect as the prevalence of respiratory symptoms in control subjects was similar to that seen in a recent large European population survey which included subjects from the UK. ${ }^{18}$ Moreover, we noted selective reporting of symptoms in both disease groups which would not be consistent with systematic recall bias. A further concern is that patients recruited from the hospital clinic were more likely to have multiple pathology than those recruited from the general population (Berkson's fallacy). ${ }^{19}$ This might explain the increased respiratory morbidity in those with inflammatory bowel disease but is less likely to explain the findings in the subjects with hypothyroidism since half of them were recruited from primary care. Nevertheless, future studies should investigate whether there is a difference in respiratory symptoms in our patient categories compared with a hospital based control group. Finally, bias due to mismatch of social class, concurrent upper respiratory tract infection, and seasonal allergy is unlikely as the study was carried out at a similar time of year for all subject groups, in neighbouring regions with similar social class distribution, and there was no excess of colds or flu in either patient group.

In summary, we have shown that patients with autoimmune hypothyroidism or inflammatory bowel disease have a higher prevalence of respiratory symptoms than controls. Furthermore, the pattern of respiratory symptoms in both immune mediated disorders was strikingly similar, suggesting that they may share similar pathogenic mechanisms. Further studies are required to investigate the pathophysiology of the excess respiratory morbidity involved and its relationship to the underlying inflammatory disorder.

\section{ACKNOWLEDGEMENTS}

The authors thank Marie Cooper for organising the Gedling participants for the follow up visits, the field workers for their assistance in collecting the data, the general practitioners and their colleagues for allowing us to use their facilities, the patient groups and people of Gedling who agreed to take part, and Sharan Gethins and Helen Williams for administrating the questionnaires in the gastroenterology outpatient clinic

\section{Authors' affiliations}

S S Birring, A J Morgan, B Prudon, I D Pavord, Institute for Lung Health, Department of Respiratory Medicine, Glenfield Hospital, Leicester LE3 9QP, UK

J F Falconer Smith, Department of Chemical Pathology, Glenfield Hospital, Leicester

R J Robinson, Department of Gastroenterology, Glenfield Hospital, Leicester

T M McKeever, S A Lewis, J R Britton, Division of Respiratory

Medicine, City Hospital, Nottingham NG5 1PB, UK

SSB is a British Lung Foundation clinical research fellow. This study was funded by the University Hospitals of Leicester NHS Trust.

\section{REFERENCES}

1 Murphy AC, Scullion JE, Heubeck CL, et al. Unexplained isolated chronic cough and organ specific autoimmune diseases. A case-control study. Thorax 2000;55:A61.

2 Birring SS, Brightling CE, Bradding $\mathrm{P}$, et al. Clinical, radiologic and induced sputum features of chronic obstructive pulmonary disease in non-smokers. A descriptive study. Am J Respir Crit Care Med 2002; 166:1078-83

3 Parle JV, Maisonneuve P, Sheppard MC, et al. Prediction of all-cause and cardiovascular mortality in elderly people from one low serum thyrotropin result: a 10-year cohort study. Lancet 2001;358:861-5.

4 Bonniere $\mathbf{P}$, Wallaert $B$, Cortot $A$, et al. Latent pulmonary involvement in Crohn's disease: biological, functional, bronchoalveolar lavage and scintigraphic studies. Gut 1986;27:919-25.

5 Camus $\mathbf{P}$, Piard F, Ashcroft T, et al. The lung in inflammatory bowel disease. Medicine 1993;72:151-83. 
6 Harvey RF, Bradshaw JM. A simple index of Crohn's disease activity. Lancet 1980; i:514.

7 Walmsley RS, Ayres RE, Pounder RE, et al. A simple clinical colitis activity index. Gut 1998;43:29-32.

8 Britton J, Pavord I, Richards K, et al. Dietary magnesium, lung function, wheezing, and airway hyper-reactivity in a random adult population sample. Lancet 1994;344:357-62

9 McKeever TM, Scrivener S, Broadfield E, et al. Prospective study of diet and decline in lung function in a general population. Am J Respir Crit Care Med 2002; 165:1299-303.

10 Burney PGJ, Laitinen LA, Perrizet S, et al. Validity and repeatability of the IUATLD (1984) bronchial symptoms questionnaire: an international comparison. Eur Respir J 1989;2:940-5.

11 Camus $\mathbf{P}$, Colby TV. The lung in inflammatory bowel disease. Eur Respir J 2000;15:5-10

12 Rose NR, Mackay IR, eds. The autoimmune diseases. 3rd ed. San Diego: Academic Press, 1998.
13 Brightling CE, Symmons FA, Birring SS, et al. A case of cough, lymphocytic bronchoalveolitis and coeliac disease. Thorax 2002;57:91-2.

14 Geddes DM, Corrin B, Brewerton DA, et al. Progressive airway obstruction in adults and its association with rheumatoid disease. Q J Med 1977;46:427-44

15 Wallaert B, Prin L, Hatron PY, et al. Lymphocyte subpopulations in bronchoalveolar lavage in Sjogrens's syndrome. Chest 1987;92:1025-31.

16 Yousem SA. Lymphocytic bronchitis/bronchiolitis in lung allograft recipients. Am J Surg Pathol 1993;17:491-6.

17 Birring SS, Brightling CE, Symon FA, et al. Lymphocytic bronchoalveolitis in idiopathic chronic cough (abstract). Thorax 2002;57(Suppl III):iii 1.

18 Janson C, Chinn S, Jarvis D, et al. Determinants of cough in young adults participating in the European Community Respiratory Health Survey. Eur Respir J 2001;18:647-54.

19 Berkson J. Limitations of the application of fourfold table analysis to hospital data. Biometrics 1946;2:47-53.

\section{LUNG ALERT}

\section{Early budesonide treatment in mild persistent asthma improves asthma control}

\ Pauwels RA, Pedersen S, Busse WW, et al on behalf of the START Investigators Group. Early intervention with budesonide in mild persistent asthma: a randomised, double-blind trial. Lancet 2003;361:1071-6

n this randomised, double blind, 3 year clinical trial the effects of budesonide in patients with mild persistent asthma for less than 2 years were assessed. 7241 patients in 32 countries aged 5-66 years received either budesonide or placebo once daily for 3 years in addition to their usual asthma medications. At least one severe asthma exacerbation occurred in 198 of 3568 patients in the placebo group but in only 117 of 3597 patients in the budesonide group, a decrease of $44 \%(\mathrm{p}<0.001)$. Life threatening asthma exacerbations occurred in 24 patients in the placebo group and in nine of those receiving budesonide $(p=0.009)$. Patients in the budesonide group had fewer courses of systemic corticosteroids and more symptom-free days $(\mathrm{p}<0.0001)$ and, compared with placebo, budesonide increased postbronchodilator $\mathrm{FEV}_{1}$ from baseline by $1.48 \%(\mathrm{p}<0.0001)$ after $\mathrm{l}$ year and by $0.88 \%$ $(p=0.0005)$ after 3 years. In children younger than 11 years the 3 year growth rate was reduced in the budesonide group by $1.34 \mathrm{~cm}$.

This study shows a substantially better outcome in patients with mild persistent asthma treated with inhaled budesonide and may provide new evidence for future therapeutic guidelines. This benefit has to be weighed against possible growth reduction in children.

G Rohde

Bergmannsheil, University Hospital, Bochum, Germany gernot.rohde@ruhr-uni-bochum.de 